\title{
Lionizing lyonization 50 years on
}

\author{
David N. Cooper
}

Published online: 26 May 2011

(C) Springer-Verlag 2011

Fifty years ago, and building upon earlier observations by Susumo Ohno and colleagues (Ohno et al. 1959), Mary Lyon proposed the random inactivation of one female $\mathrm{X}$ chromosome early in embryogenesis to account for the mottled phenotype of female mice heterozygous for specific coat colour gene mutations.

"It is here suggested that this mosaic phenotype is due to the inactivation of one or other X-chromosome early in embryonic development. If this is true, pigment cells descended from cells in which the chromosome carrying the mutant gene was inactivated will give rise to a normal-coloured patch and those in which the chromosome carrying the normal gene was inactivated will give rise to a mutantcoloured patch" (Lyon 1961).

A key element of Lyon's hypothesis was the random nature of X-inactivation (subsequently also given the eponym, 'lyonization'), affecting either the maternally or the paternally inherited X chromosome. Thus, all female mammals are effectively mosaics for two distinct cell lines, with either the maternal or the paternal $\mathrm{X}$ chromosome being inactivated. The relative proportion of the two cell lines (the $\mathrm{X}$-inactivation pattern) in any given individual may, however, be skewed, resulting in an X-inactivation pattern where $>80 \%$ of the cells exhibit preferential inactivation of one or other X chromosome. Unfavourable skewing can be important in clinical practice, e.g. in cases of clinically affected female carriers of a specific X-linked

D. N. Cooper $(\square)$

Institute of Medical Genetics, Cardiff University,

Heath Park, Cardiff CF14 4XN, UK

e-mail: cooperDN@ cardiff.ac.uk condition where the $\mathrm{X}$ chromosome carrying the mutant allele is predominantly the active $\mathrm{X}$ chromosome (Orstavik 2009).

In principle, $\mathrm{X}$-inactivation ensures dosage equality between males and females in terms of the number of transcriptionally active $\mathrm{X}$-linked genes. However, it is now known that a subset of $\mathrm{X}$-linked genes escape silencing by $\mathrm{X}$-inactivation and these genes continue to be expressed from both $\mathrm{X}$ chromosomes. It is also now known that the process of $\mathrm{X}$-inactivation involves a number of different mechanisms including DNA methylation, RNA-mediated gene silencing, and changes in chromatin modification/ organization. It is controlled by a specific region on the long arm of the $\mathrm{X}$ chromosome (Xq13.2) termed the $\mathrm{X}$-inactivation centre. Within this $\mathrm{X}$-inactivation centre are a number of genes (including XIST and its antisense transcript TSIX) and cis-regulatory elements that are required for $\mathrm{X}$-inactivation to occur. However, the precise details of the mechanism of $\mathrm{X}$-inactivation (and the mechanism underlying escape from inactivation) still remain to be ironed out.

To celebrate the 50th anniversary of Lyon's seminal paper, we have put together a Special Issue of this journal devoted to the topic of X-inactivation. A collection of 13 research and review articles, written by key workers in the field, provide an overview of current knowledge pertaining to the mechanism of $\mathrm{X}$-inactivation, its evolutionary emergence, and its relevance to inherited disease.

Although Mary Lyon officially retired more than 20 years ago, she has continued to make important contributions to her eponymous area of research, most notably by her hypothesis of a role for LINE elements in X-inactivation (Lyon 1998). Judging by recent data (Chow et al. 2010; Gunter 2010), the "Lyon LINE (repeat) hypothesis" may well in future years come to be seen to be at least as prescient as the original Lyon hypothesis whose anniver- 
sary we celebrate in this Special Issue. By way of a tribute to the unique contribution that Mary Lyon has made to this area of research over the last half century, we dedicate this Special Issue to her.

\section{References}

Chow JC, Ciaudo C, Fazzari MJ, Mise N, Servant N, Glass JL, Attreed M, Avner P, Wutz A, Barillot E, Greally JM, Voinnet O, Heard E (2010) LINE-1 activity in facultative heterochromatin formation during X chromosome inactivation. Cell 141:956-969
Gunter C (2010) X inactivation: get in LINE for silencing. Nat Rev Genet 11:528-529

Lyon MF (1961) Gene action in the X-chromosome of the mouse (Mus musculus L.). Nature 190:372-373

Lyon MF (1998) X-chromosome inactivation: a repeat hypothesis. Cytogenet Cell Genet 80:133-137

Ohno S, Kaplan WD, Kinosita R (1959) Formation of the sex chromatin by a single $\mathrm{X}$-chromosome in liver cells of Rattus norvegicus. Exp Cell Res 18:415-418

Orstavik KH (2009) X chromosome inactivation in clinical practice. Hum Genet 126:363-373 